\title{
Frothing Phenomena in Phosphate Gangue Flotation from Magnetite Fines with Fatty Acid based Collector and MIBC Frother
}

\author{
A. Vilinska ${ }^{1}$, A. Fredriksson ${ }^{2}$, G. Adolfsson ${ }^{2}$ and K. Hanumantha Rao ${ }^{1, *}$ \\ ${ }^{1}$ Division of Sustainable Process Engineering Department of Civil, Environmental and Natural Resources Engineering \\ Luleå University of Technology, SE-971 87 LULEA, Sweden
}

${ }^{2} R$ \& D Mineral Processing, LKAB, SE-98131 KIRUNA, Sweden

\begin{abstract}
Dephosphorization of magnetite fines at LKAB is carried out by floating the phosphorous gangue using a fatty acid based collector namely Atrac and MIBC frother. Excessive and stable froth formation in flotation led to an unnecessary step of diluting the phosphate froth gangue component to transport to tailings damn. In this study the influence of reagents and their combinations on the froth production and stability was examined. Methods involved surface tension measurements, froth production and froth quality tests, zeta-potential and spectroscopy methods to resolve the possible collector and frother interactions. The froth production and quality was evaluated in the presence of apatite and magnetite solid particles as well.

The volume and quality of froth produced by Atrac was found to be a function of concentration and $\mathrm{pH}$, while MIBC formed non-stable froth with approximately the same volume independent of concentration. When Atrac is combined with MIBC the froth production and quality is enhanced. As no interaction was detected between the reagents, the increase of froth production is thought to be a change in electrostatic forces around the collector molecule by the frother. Atrac has a higher contribution to frothing than MIBC. Surface active partially hydrophobic apatite particles were observed to be the main factor causing extremely stable froth.
\end{abstract}

Keywords: Flotation, Froth characteristics, Phosphate, Magnetite, Surface tension, Zeta-potential.

\section{INTRODUCTION}

Foam is a dispersion of a gas in a liquid and always forms from mixtures, while pure liquids never foam. The conditions to create froth are that one of the components must be surface active and the foam film has to be elastic. Aqueous solutions of surfactant liquids that do not form micelles show low foamability. Cohesive forces of the hydrophobic chain also increase the foamability. Foaming properties of surfactant solutions may be modified by the presence of other organic materials. Organic additives may decrease the CMC of the surfactant solution and enhance the foam production and stability or increase the mechanical strength of foam films [1]. Coalescence of bubbles is reported to occur in the presence of inorganic electrolytes. Gravitation causes drainage of liquid between the air bubbles and thins the liquid film to an eventual collapse of the froth.

In general, the characteristics of froth are assessed in terms of its brittleness, stability, bubble size distribution, drainage, and readiness to collapse when air supply is disconnected. These characteristics are known to be influenced

*Address correspondence to this author at the Division of Sustainable Process Engineering Department of Civil, Environmental and Natural Resources Engineering Luleå University of Technology, SE-971 87 LULEA, Sweden; Tel: +46-920 491705; Fax: +46-920 97364;

E-mail: Hanumantha.rao@ltu.se by the interactions among the reagents. The chemical structure of the surfactant (collector) molecule was to exert a most dramatic influence on froth characteristics and surface activity in general. For example, sodium oleate and pine oil were found to be incompatible in certain ratios. As far as flotation is concerned, the interaction between collector and frother, which depend on its structure and ionic composition of the solution, appear to be beneficial within certain limits of concentrations. Outside such limits, these interactions have adverse effect. The synergetic effects of reagents on froth formation has received little or no attention in flotation literature, but could be very significant in column flotation since the column froths are subjected to the cleaning operation or removal of fine hydrophilic particles.

The main requirement of flotation froths is to cause an efficient high-rate mineralization of bubbles selectively. Flotation froths are studied as components of two-phase systems, although the presence of solids or even slight variation in the composition of solid phase is known to affect the behaviour of froth formation. Particles stabilize the foams since they stick in the Plateau borders and lower the drainage of liquid, and also when the particles themselves are surface active. There are several observations that the size of particles and its degree of hydrophobicity, and the extent of solids loading influence the froth stability. The best foam stability is achieved, when the contact angle of particles with water is around $90^{\circ}$. 
The dephosphorization of magnetite fines at LKAB is carried out by floating the phosphorous gangue using a fatty acid based collector and MIBC frother. The phosphorous flotation process is conducted in a battery of conventional flotation cells and the magnetite concentrate (flotation tails) is cleaned in a column flotation cell and the float phosphate gangue is dispatched to tailings dam. Excessive and stable froth formation in column flotation led to the necessity of diluting the phosphate float gangue component to transport to the tailing dam. This problem arose due to the stability of froth even after the cessation of air supply; the purpose behind this work plan is to avoid the dilution step while understanding the synergetic effect of collector and frother on froth formation and stability in the presence and absence of fine apatite particles.

\section{MATERIALS AND METHODS}

\subsection{Minerals}

Museum grade magnetite and apatite was crushed and sorted to different size fractions by wet sieving. Two fractions were selected to perform the studies. The coarse fraction consisted of flotation size $-105+38 \mu \mathrm{m}$ particles representing the flotation process. The fine fraction of -38 $\mu \mathrm{m}$ particles was chosen for its higher surface area and smaller particle size, which particles also include in the flotation feed at LKAB.

\subsection{Solution Preparation}

Solutions of Atrac and MIBC were prepared with deionized water at the desired concentrations and $\mathrm{pH}$. Atrac was first solubilized in $1 \mathrm{M} \mathrm{NaOH}$ solution (Atrac:hydroxide $=2: 1$ ) and a stock solution of $100 \mathrm{ppm}$ was prepared and the $\mathrm{pH}$ of the solution was adjusted as desired. The stock solutions were prepared daily. The $\mathrm{pH}$ was controlled before all the measurements. As the flotation process $\mathrm{pH}$ is around 8.5, the same $\mathrm{pH}$ was maintained in the measurements unless otherwise specified. Atrac collector is a combination of a monoester of a dicarboxylic acid of the general formula $\mathbf{I}$ and a fatty acid II shown below, in which R' and R"' are aliphatic hydrocarbon chains, R" is a hydrocarbon radical and $\mathrm{A}$ is an alkylene oxide group (Swiatowski, et al. 1992) [2].<smiles>[R]OC(=O)[R](=O)C(=O)O</smiles>

I<smiles>[R][Co]=O</smiles>

II

\subsection{Surface Tension Measurements}

The surface tension was measured with Krûss K100 tensiometer. The plate method with a platinum plate was employed. Each sample was measured several times and the average value was reported. After each test the liquid was replaced by a fresh one and the platinum plate was carefully cleaned.

\subsection{Turbiscan Measurements}

Froth production tests were carried out by Turbiscan LAb and Tlab EXPERT 1.13 software. The cylindrical glass measurement cell is filled with the sample. The light source Light source is a pulsed near infrared. Two synchronous optical sensors Optical sensors receive the light transmitted through the sample and light backscattered by the sample respectively at the same time. The optical reading head scans the length of the sample (up to $55 \mathrm{~mm}$ ), acquiring transmission and backscattering data every $40 \mu \mathrm{m}$. From the transmission and backscattering data curves are created according to the scan length. These curves provide the

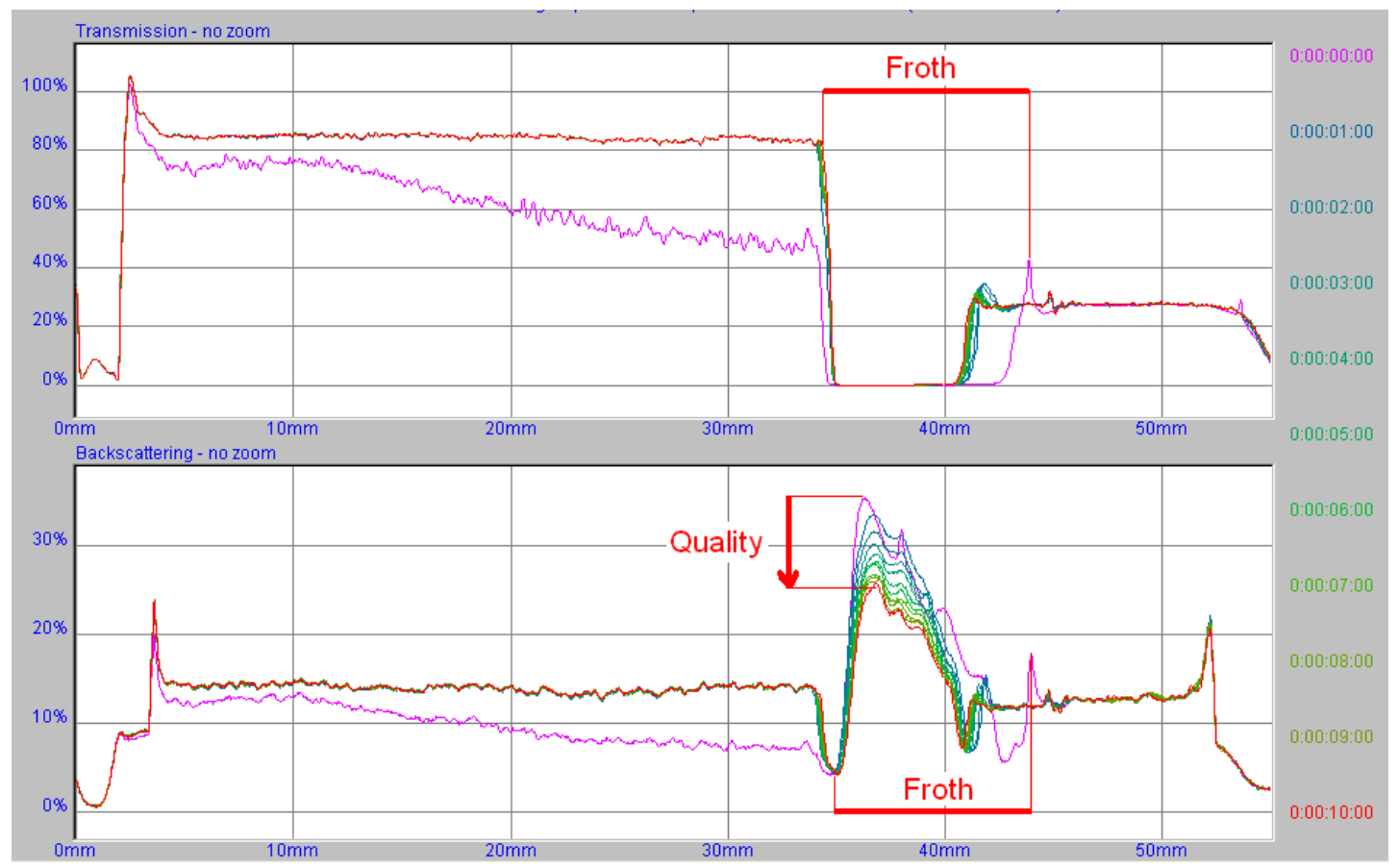

Fig. (1). Turbiscan measurement and data outcome used for the analysis. 
transmitted and backscattered light flux in percentage relative to standards as a function of the sample height in $\mathrm{mm}$. These profiles provide a macroscopic fingerprint of each sample at a specific time. In a schematic way, a transmission is used to analyze clear to turbid dispersions and backscattering is used to analyze opaque dispersions. The principle is presented in Fig. (1).

As froth bubbles are opaque to light, it will appear as loss of signal and $0 \%$ transmitted light $(\mathrm{T})$ on the upper diagram (Fig. 1). On the other hand the bubbles also reflect the light back and increase the backscattered signal (BS) on the lower diagram. The scanning is repeated every minute for the total of 10 minutes and each coloured line represents one scan. The purple/pink is the scan at zero time, e.g. immediately after the insertion, and the red line is after 10 minutes. To estimate the amount of produced froth (froth height), one can use the transmitted light diagram or the backscattered one. The transmitted light may contain the meniscus also, so the beginning of the froth was estimated from the increase of backscattered signal. The top of the froth was taken from the last peak on BS and the first one on the T graph after the froth caused drop of signal. The position of both is equal. There is also a change in the froth quality visible on the BS diagram. As the "band" of the foam is decreasing with time, the froth is degrading. Smaller bubbles create whiter foam and more light is reflected back. On the other hand bigger bubble size produce lower BS values. Often the degradation starts before the drop in froth height by bubble burst and coalescence and this can be recorded with Turbiscan. The bigger is the decrease in backscattering, the bigger the degradation in the froth. To have a numerical outcome, the quality parameter was calculated:

$$
\text { Froth quality }=\frac{B S_{\max }}{B S_{\max }-B S_{\min }}
$$

I) $\mathrm{BS}_{\max }$ is the highest $\mathrm{BS}$ value reached, $\mathrm{BS}_{\min }$ the $\mathrm{BS}$ value at the same position after 10 minutes. The computation reflects the change of the BS as well as the highest reached value, so the initial quality of the froth is also incorporated in this parameter. Lower values mean the froth degradation is rapid and the bubbles are big, while higher values depict stable froth and consist of fine bubbles.

ii) For the comparison of the data generated by Turbiscan, they were compared with the froth height achieved in a glass column. $50 \mathrm{ml}$ of solution was poured into column with perforated bottom part and aerated with air for $30 \mathrm{~s}$, at a flow rate of $120 \mathrm{ml} / \mathrm{min}$. The two had a linear relationship with the following regression equation:

iii) Column froth height $=-96.3+20.6$ Turbiscan froth height $\left(\mathrm{R}^{2}=97.6 \%\right)$.

Thus both methods were considered as equal. For the tests $15 \mathrm{ml}$ of the sample was used in the sample holder, and the samples were shaken for 20 seconds before the measurement. Solid content was $1 \mathrm{~g} / \mathrm{l}$ for the mineral suspensions. This procedure ensures the same amount of air passing through the sample every time.

\subsection{Zeta-potential Measurements}

Zeta potential measurements were made using Zeta Compact equipped with video and Zeta4 software. The software allows the direct reading of zeta-potential calculated from the electrophoretic mobilities using Smoluchowski (1921) equation. The result is a particle distribution diagram, from which the mean mobilities are recalculated to zeta-potential values. Atrac solutions of respective $\mathrm{pH}$ were prepared at a constant ionic strength, using a $10^{-2}$ and $10^{-3}$ molar solution of monovalent electrolyte $\mathrm{KNO}_{3}$. Atrac concentration was kept constant at $16 \mathrm{ppm}$ for almost all pHs. 357631271 At pH 2 the solutions were not recordable except at 100,x dilution which is a much lower concentration ( $0.16 \mathrm{ppm})$, but was necessary due to the limited solubility of Atrac at acidic $\mathrm{pH}$. The lower ionic strength experiment was performed immediately after the $\mathrm{pH}$ adjusting, while the $10^{-2}$ molar samples were left for 30 minutes conditioning time before the measurements. The $\mathrm{pH}$ was re-recorded before the measurements.

\subsection{Spectral Analysis}

UV-vis and Raman spectra were recorded to examine the possible interactions of the collector and frother. The concentration of $50 \mathrm{ppm}$ was chosen from the previous surface tension results. Atrac at $50 \mathrm{ppm}$ concentration and

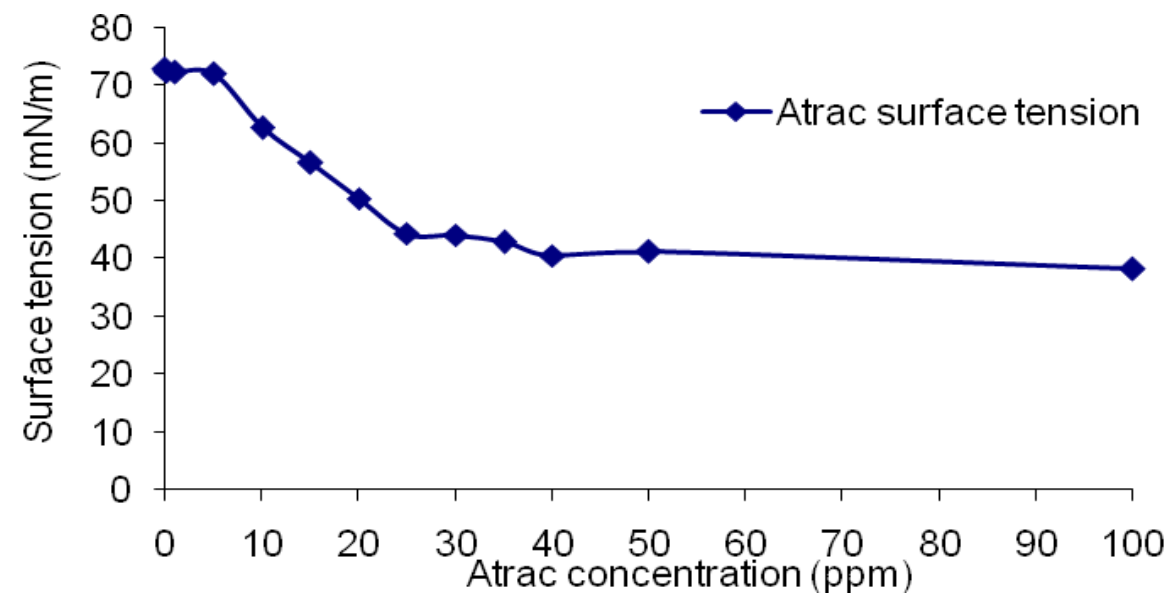

Fig. (2). Surface tension of aqueous solution of Atrac collector at pH 8.5. 
MIBC at $50 \mathrm{ppm}$ at $\mathrm{pH} 8.5$ were tested first and a mixture of $1: 1$ of both was examined later.

\section{RESULTS AND DISCUSSION}

\subsection{Surface Tension of Collector and Frother Solutions}

The surface tension reduction by the collector and frother molecules themselves and their mixture at a given total concentration could be a way to determine the molecular interactions in solution. The efficiency of surface tension reduction by a surfactant is defined as the solution phase concentration required to produce a given surface tension reduction. Thus, surface tension of aqueous solutions of Atrac collector and MIBC frother independently, and combined have been determined at different concentrations and $\mathrm{pH}$. The surface tension and concentration curves for collector and frother are presented in Figs. (2 and 3) respectively. The $\mathrm{pH}$ of the solutions was kept constant at 8.5 corresponding to the flotation $\mathrm{pH}$. The surface tension of water decreases after 5 ppm of Atrac concentration (Fig. 2). The critical micelle concentration is around $25 \mathrm{ppm}$ and above which concentration, no significant decrease of the surface tension was observed. A minor discontinuity of surface tension is visible from 25 to $40 \mathrm{ppm}$ and probably is a result of impurities present in the sample [3,4]. Considering an approximate molecular weight of Atrac as $300 \mathrm{~g} / \mathrm{mol}$, comparable to oleic acid collector, the critical micelle concentration (CMC) of Atrac is found to be around $1 \times 10^{-4} \mathrm{M}$. The substance can be considered as very surface active with a strong affinity to the air-water interface.

The reduction in surface tension of water with increasing MIBC concentration (Fig. 3) shows that it is lesser surface active compared to Atrac. To achieve a comparable decrease in surface tension with Atrac, a concentration of $1000 \mathrm{ppm}$ and more was necessary. The surface tension is seen to decrease continuously with increasing concentration and CMC could not be estimated from this curve. From the character of this surface tension curve, MIBC can be considered to be an organic additive and not a real surfactant [5]. However the decrease in surface tension illustrates frother molecules preference to adsorb at the liquid-air interface.

Fig. (4) shows the surface tension of collector aqueous solutions at 10, 15 and $22 \mathrm{ppm}$ concentrations as a function of $\mathrm{pH}$. The surface tension at $22 \mathrm{ppm}$ collector concentration, closely corresponding to the CMC, is relatively constant at about $50 \mathrm{mN} \mathrm{m}^{-1}$, but increases above $\mathrm{pH}$. The surface

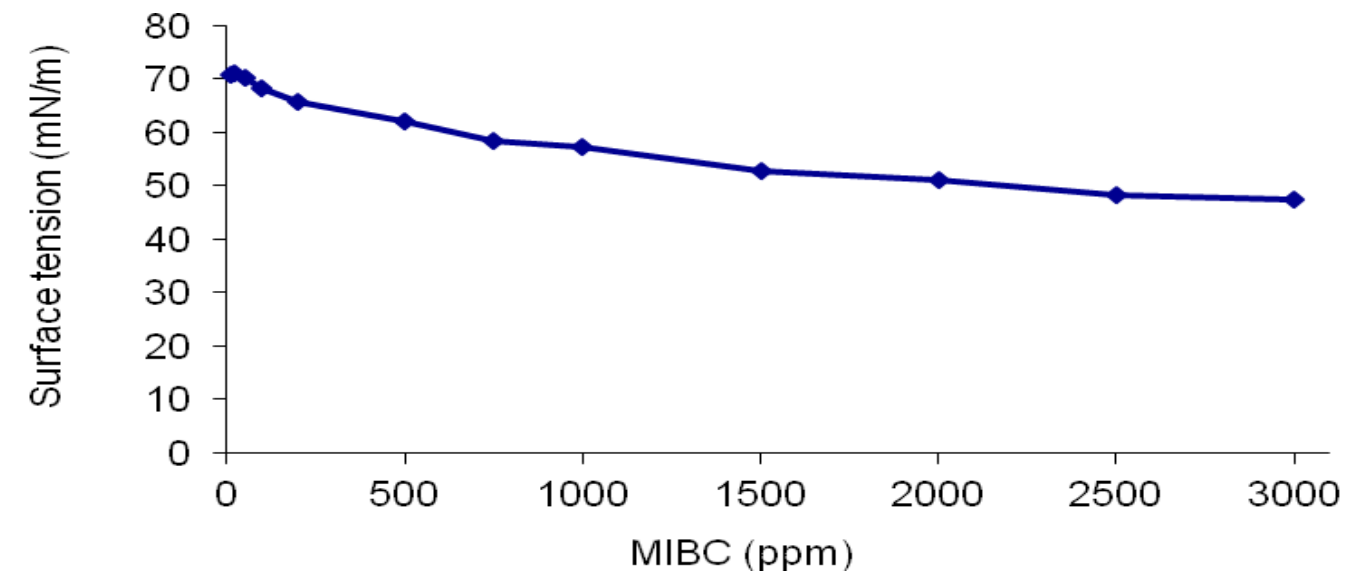

Fig. (3). Surface tension of aqueous solution of MIBC frother at $\mathrm{pH} 8.5$.

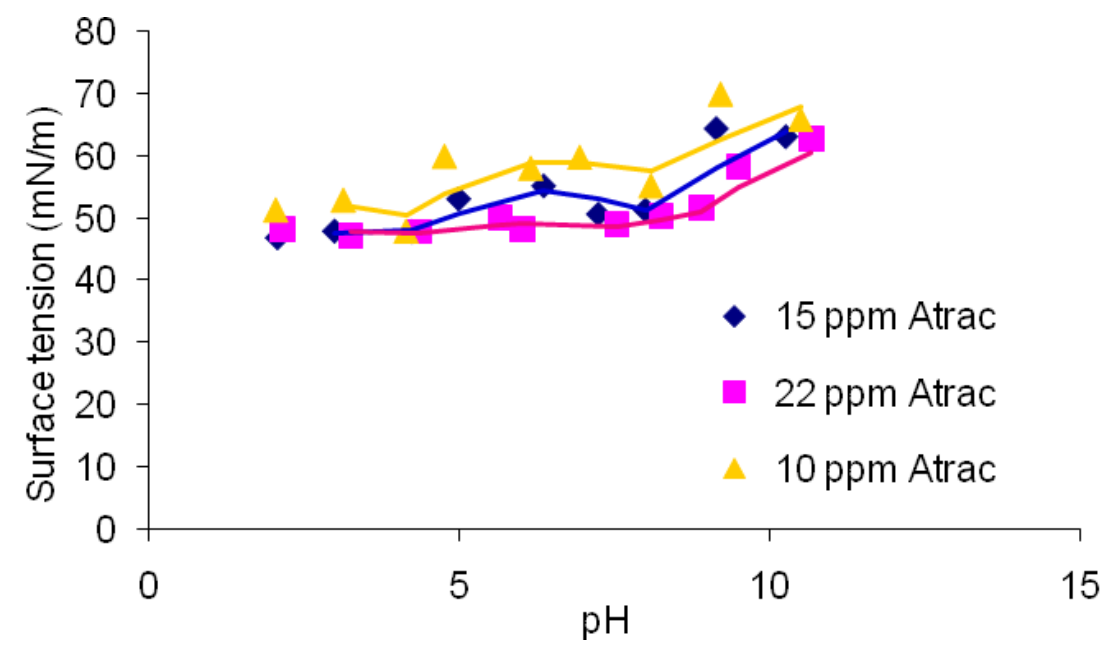

Fig. (4). Surface tension of aqueous solutions of collector as a function of $\mathrm{pH}$ at three initial concentrations. 
tension at lower concentrations of 15 and $10 \mathrm{ppm}$ are found to be more dynamic and fluctuated within the measurement time of a sample. The results followed the same pattern at all the concentrations with a lesser reduction in surface tension at lower concentrations. The increase in surface tension above pH 8 could be due to an increase in the solubility of Atrac anionic collector where the molecules favour to be in the bulk of solution to a certain extent. The consideration of Atrac as anionic surfactant is supported by the zetapotentials of its colloidal species presented in Fig. (5).

Atrac is intensively negatively charged and it is an anionic surfactant (Fig. 5). The zeta potential was recorded with Atrac suspensions immediately after $\mathrm{pH}$ adjustment and after reaching 30 minutes equilibrium time. For both suspensions, several mobility distribution peaks were observed, characterizing a multi-component system from the point of surface charge. The charge characteristics for both suspensions are similar and longer equilibration time caused some deviations at higher $\mathrm{pH}$ values. The local decrease of negative surface charge around $\mathrm{pH} 8$ and 6 corresponds to a lesser reduction in surface tensions at these $\mathrm{pH}$ values. A good correspondence between zeta-potential and surface tension values of Atrac is observed, i.e., less negatively charged species $=$ lower solubility $=$ increased concentration on the water-air interface = lower surface tension.

The influence of frother on surface tension reduction by the collector is shown in Fig. (6). In this figure, the surface tension curves demonstrate that the presence of 5 and 10 ppm concentration of frother in collector solution hardly has any effect on surface tension. A small increase of surface tension is observed for $10 \mathrm{ppm}$ of frother addition compared to pure collector. The presence of frother caused some irregularities in surface tension curve between 15 and 40 ppm concentration. Initially considered as an experimental error, but the same trend was observed after repeating the measurements. It is not clear, whether it is a result of some interactions or just simply showing the signs of "impurities" in the surfactant. For the 5 and $10 \mathrm{ppm}$ of frother addition in collector solutions, the local increase appeared at $20 \mathrm{ppm}$ and 30-35 ppm respectively. Excluding these local disturbances, the surface tension of collector is not reduced significantly with frother addition.

The reduction in surface tension at different collector and frother compositions is presented in Fig. (7). These results once again show that the addition of frother has no effect on surface tension reduction of the collector solutions. There is no synergetic effect of frother with the collector. The surface

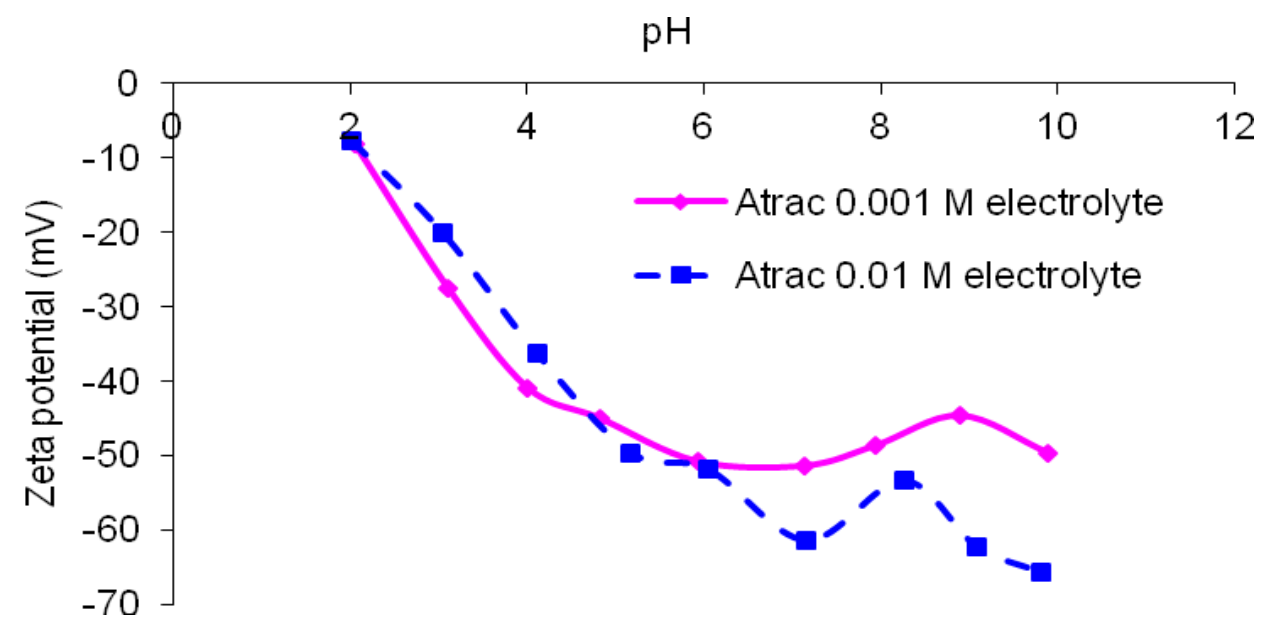

Fig. (5). Zeta-potential versus $\mathrm{pH}$ of collector colloidal species at 0.01 and $0.001 \mathrm{M}$ ionic strength.

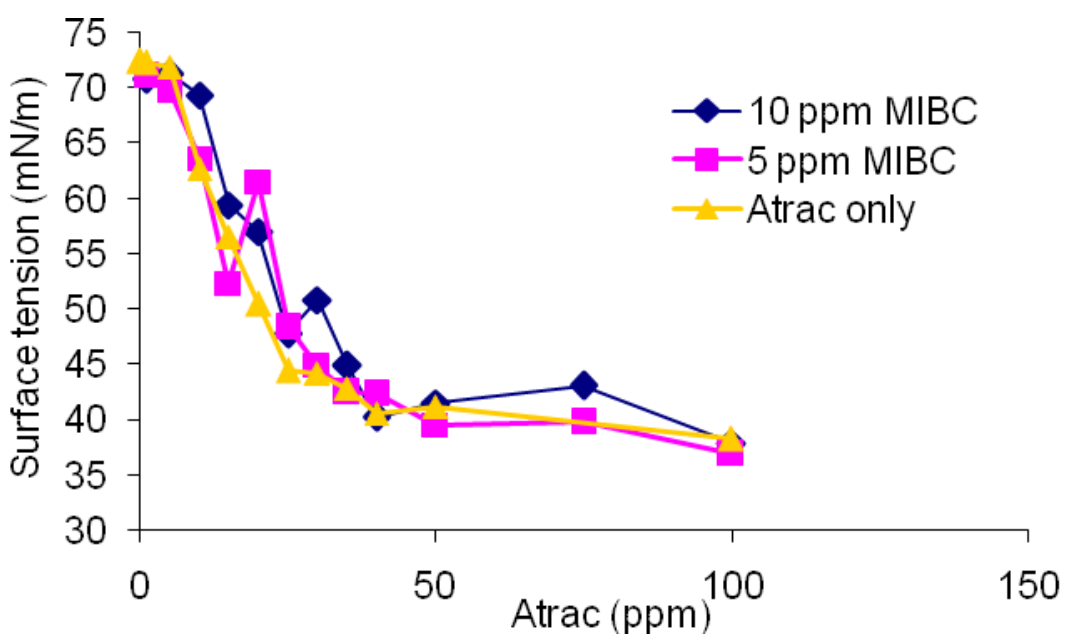

Fig. (6). Surface tension of collector aqueous solutions in the presence and absence of frother at pH 8.5. 
tension is marginally increased at $4: 1$ composition and the increase was more noticeable with an increased frother concentration in the composition of $1: 1$. This increase is due to the decrease of collector concentration in the total concentration and therefore lower adsorption at the air-water interface compared to the pure collector solutions. Some local artefacts appeared again. These artefacts are more intense for higher concentration of frother in the composition. For the 4:1 ratio, the local increase appeared at 40 ppm total concentration (consisted of 32 ppm Atrac and 8 ppm MIBC) which is identical with the local maximum found for Atrac in the presence of 10 ppm MIBC (Fig. 6). For higher frother level in the composition, the local maxima became wider. At these points some interaction between collector and frother was presumed but the conducted spectroscopic measurements didn't confirm any as no new peaks or peak position changes were observed (data not shown).

\subsection{Froth Formation and Stability}

The capacity of the Atrac collector to form froth and its quality as defined earlier is presented in Fig. (8). The froth formation by collector at $\mathrm{pH} 8.5$ is considerably good. The volume of froth and its quality increase with increasing concentration of collector. While the froth height had a linear increase with concentration, the quality had its local maximum at $30 \mathrm{ppm}$ and was constant over $50 \mathrm{ppm}$.

The frothing behaviour of collector versus $\mathrm{pH}$ at three initial concentrations is given in Fig. (9). Both the amount and quality of froth found to be $\mathrm{pH}$ dependent and at low acidic $\mathrm{pH}$ values the frothing capacities were minimal. Below pH 6, the production of froth is lower and the bubbles were unstable. Above $\mathrm{pH}$ 6-7 the froth production begins to rise and sufficient froth developed at the flotation $\mathrm{pH}$ 8.5. The froth quality is also seen to increase with increasing $\mathrm{pH}$ and culminated around $\mathrm{pH}$ 8.5-9. Further increase of $\mathrm{pH}$ didn't increase the froth quality. There are two major forces capable to stabilize the lamellas of bubbles in the froth: cohesive forces and electrostatic forces [1]. Cohesive forces acting between the long hydrophobic carbon chains of the molecules could stabilize the froth, as well as strong electrostatic repulsive forces in between charged molecules. High micelle stability works against froth formation [6, 7]. Below $\mathrm{pH} 6$ the high micelle formation might have prevented the production of stable bubbles. As revealed by the zeta potential measurements, Atrac is highly charged at higher $\mathrm{pH}$ and has a decreased solubility at lower $\mathrm{pH}$. Decreased solubility at acidic $\mathrm{pH}$ decreases the amount of surfactant at the interface and the frothing capacity. At

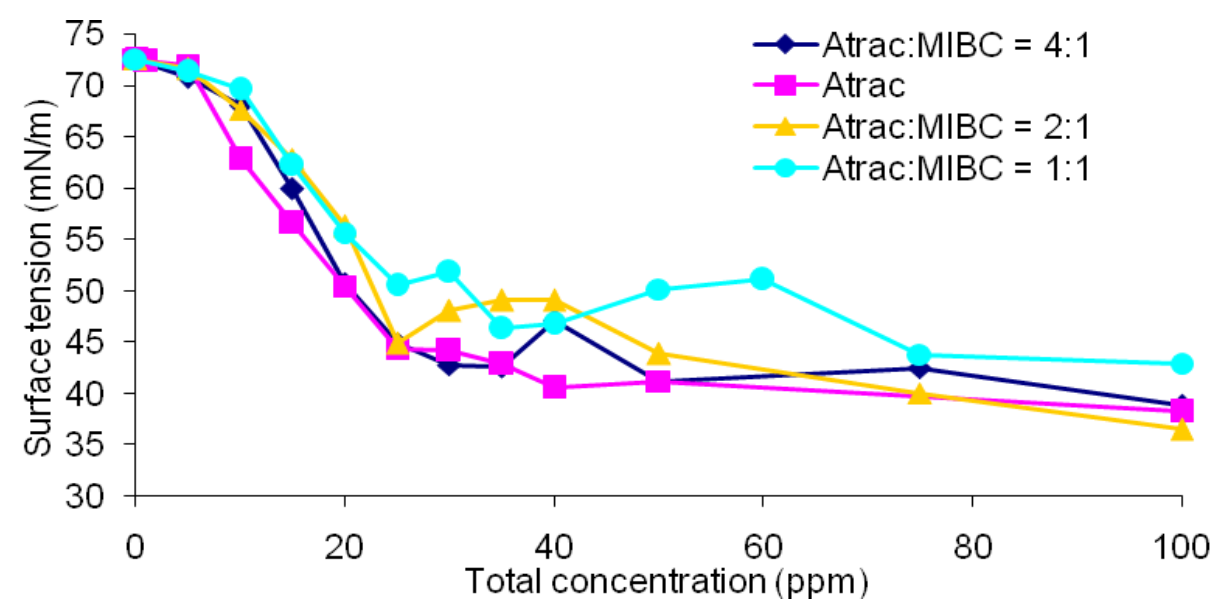

Fig. (7). Surface tension of aqueous solutions of collector and frother at different compositions as a function of total concentration at pH 8.5.

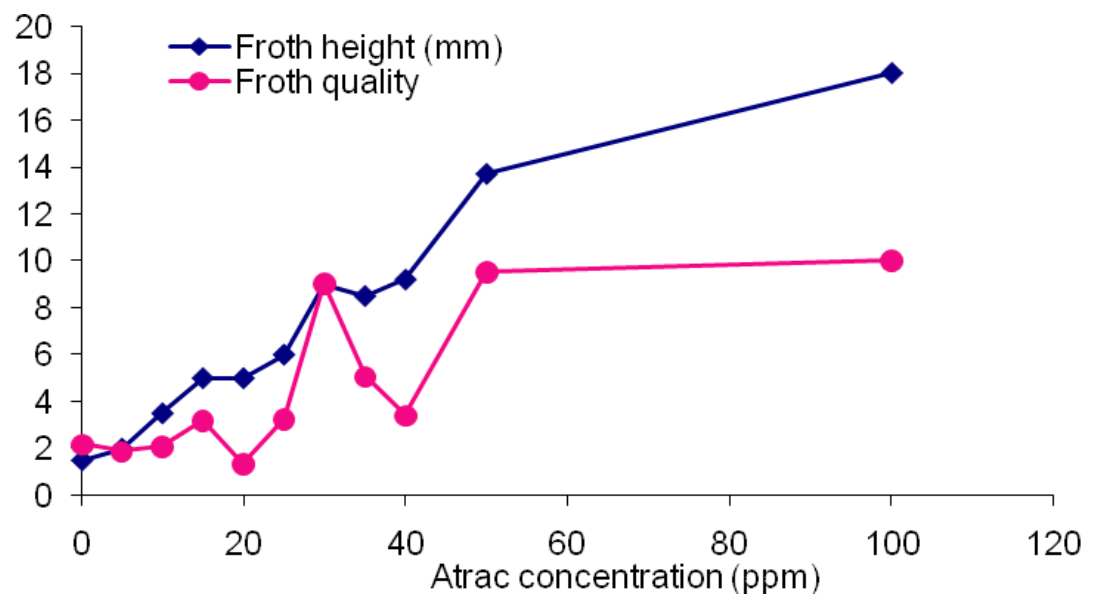

Fig. (8). Froth height and quality as a function of collector concentration at $\mathrm{pH} 8.5$. 


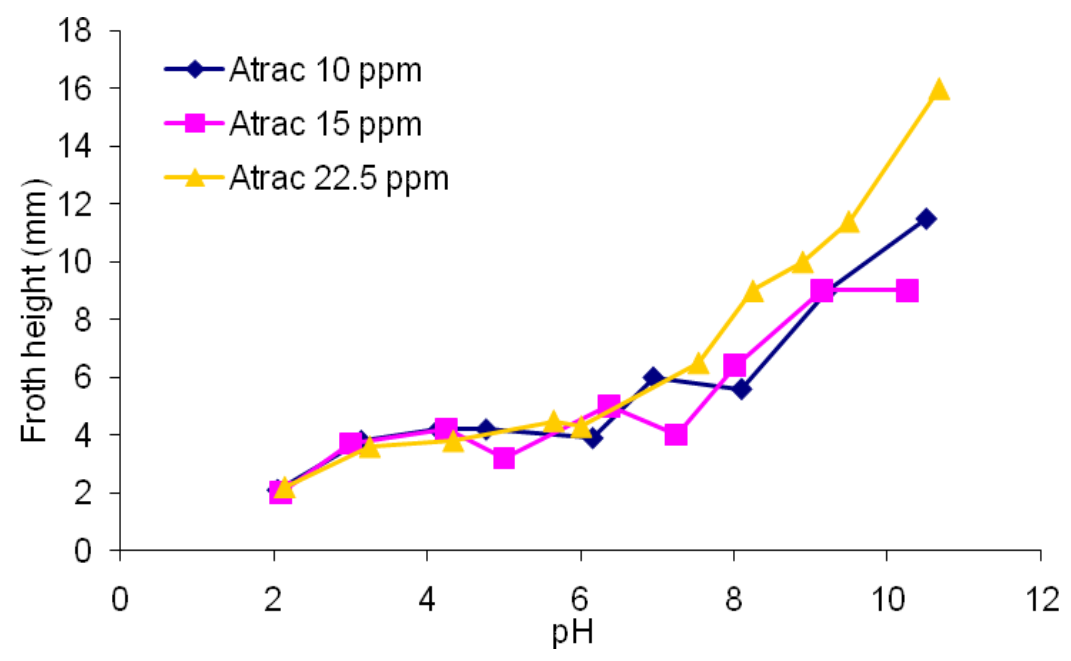

Fig. (9). Influence of $\mathrm{pH}$ on froth formation of different concentrations of collector solutions.

higher $\mathrm{pH}$ the molecule is highly charged, the electrostatic repulsive force between the surfactant molecules may promote froth formation and stabilize the lamellae. The frothing of Atrac could be assigned to electrostatic repulsive forces acting in-between the dissociated molecules. This supposition is verified by decreased froth production after $\mathrm{NaCl}$ and $\mathrm{KNO}_{3}$ addition.

MIBC is used as a frother and is capable to create froth over $5 \mathrm{ppm}$ concentration. The amount of produced froth was lower in comparison with Atrac and kept within the interval of 4-8 $\mathrm{mm}$ (data not shown). No increase of froth production with the concentration was recorded. The highest froth was achieved using diluted solutions of MIBC and the froth production declined over $1000 \mathrm{ppm}$. The quality of froth was low; the froth consisted of rather bigger bubbles and was unstable. MIBC can be considered as a non-micelle forming organic additive, similar to ethanol. These materials are capable to create froth as the surface tension of the liquid is decreased, but the lack of micelle formation and surface elasticity is causing the bubbles to burst [5].

No effect of frother on surface tension of aqueous collector solutions was noticed earlier but the amount of froth formation increases with frother addition (Fig. 10). The effect was more predominant at lower collector concentrations. Over 50 ppm of collector, the frother didn't increase the frothing of collector solutions. Frother also increased the quality of the produced froth. The quality of the froth doesn't seem to depend on the frother concentrations, because the curves are overlapping (Fig. 11). The maximum froth quality was achieved at $35 \mathrm{ppm}$ of collector while a collector solution alone exhibited this at $30 \mathrm{ppm}$. In general, frother seems to have a higher effect on the amount of froth formation rather than on froth quality. Since micelles can solubilize organic additives and thereby remove them from the interface, much larger amounts are required above the CMC than below [1]. That's why the effect of frother found to be significant at low collector concentrations.

At the same total concentration of collector and frother combined, the froth production was enhanced with the presence of frother relative to the total concentration of collector alone (Fig. 12). This effect was evident up to 50 ppm total concentration, above which the froth production reached saturation. Froth quality improved, and in the regions of local artefacts, the froth quality reached its

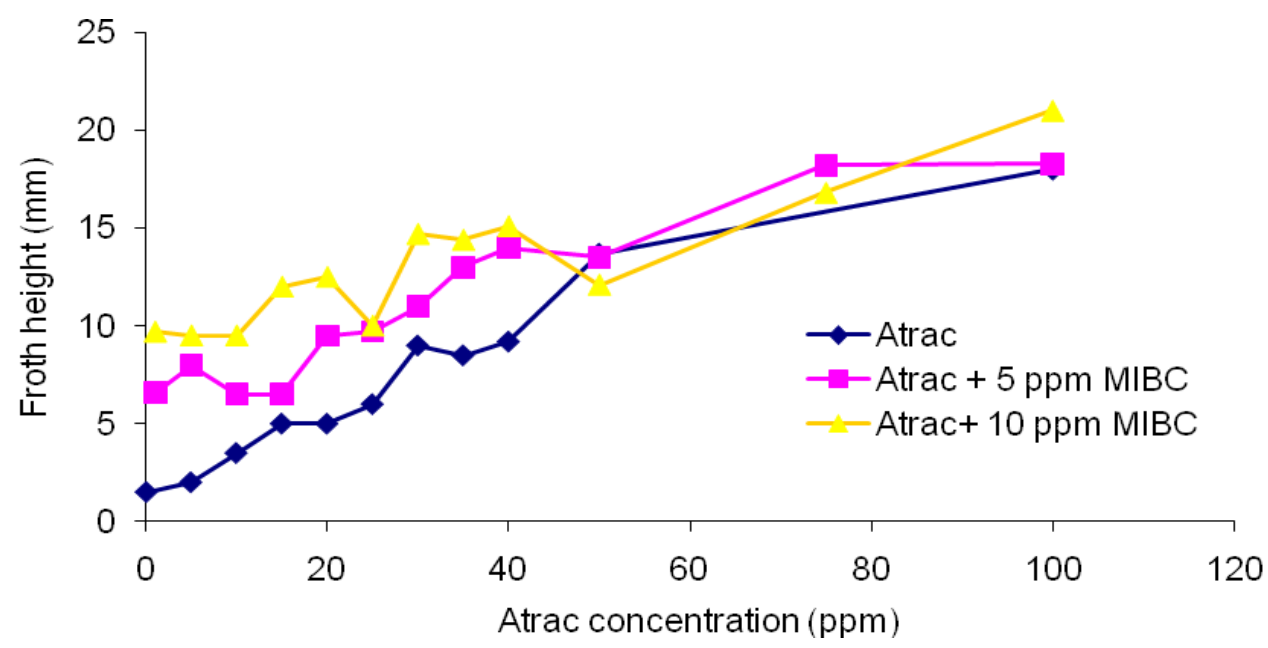

Fig. (10). Froth formation in the absence and presence of frother as a function of collector concentration at pH 8.5. 


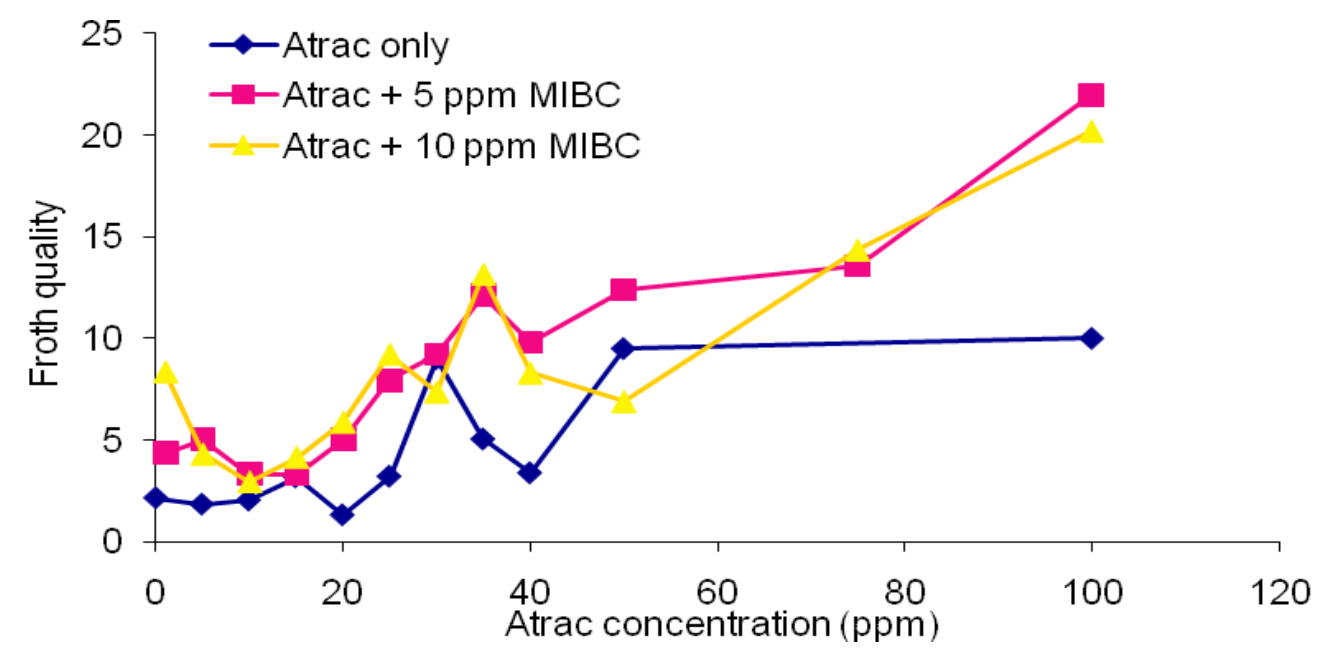

Fig. (11). Froth quality in the absence and presence of frother as a function of collector concentration at $\mathrm{pH}$ 8.5.

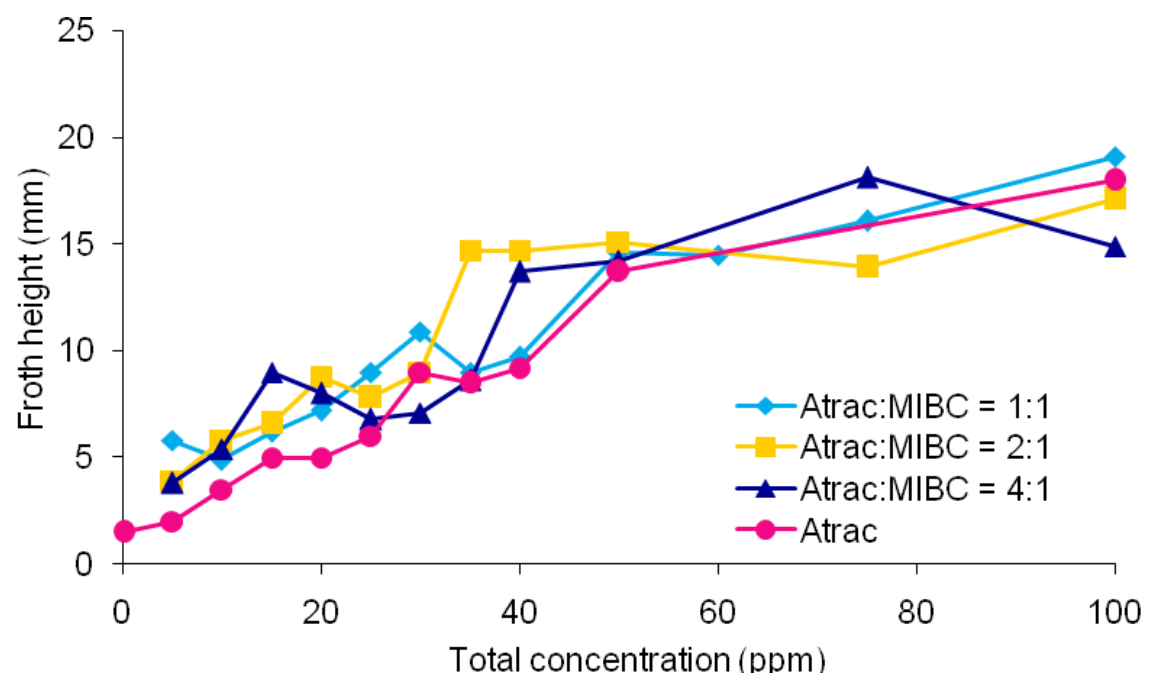

Fig. (12). Froth formation at different collector and frother composition as a function of total concentration at pH 8.5.

maximum (Fig. 13). As the ratio of collector decreased in the mixtures, the froth quality peaked at higher total concentrations. Increasing the ratio of MIBC didn't increase the froth quality. The highest quality was achieved with 4:1 collector/frother, overdose of the frother became rather counterproductive in terms of froth quality and stability.

The possible explanation of the increased frothing is the reduction of dielectric constant of the aqueous phase [8, 9]. This may lead to increased repulsion of the charged polar parts of the molecules. Because the froth production is significant when the molecules are in the "charged" state, is that a result of a stronger electrostatic repulsion in between charged collector molecules. The reduction of dielectric constant may lead to increased repulsive forces and to increased froth production and quality. Strong repulsion between the molecules are opposing micellization and increasing the CMC.

\subsection{Froth Formation and Stability in the Presence of Solids}

Different concentrations of collector were introduced into $1 \mathrm{~g} / \mathrm{l}$ suspensions of apatite and magnetite minerals at $\mathrm{pH} 8.5$ and the froth formation was evaluated. The results on froth height and quality are presented in (Figs. 14 and 15) respectively. Formation of froth in pure collector solution is also given for comparison purposes. When apatite was used, instead of a real froth, some floating flocs were formed. The apatite surface has become hydrophobic due to the adsorption of collector and thus the particles are positioning at the air-liquid interface. The height of such froth found to be limited to a maximum $7-8 \mathrm{~mm}$ at any collector concentration. The presence of either fine or coarse apatite particles has similar effect on froth formation but the fines created slightly more froth. It is not clear whether the plateau in froth formation is due to the collector adsorption on the mineral surface and depletion from the solution, or the presence of flocs preventing the residual collector to form bubbles. In this case the mineral particles are surface active and hydrophobic [1]. At high hydrophobicity the particles tend to leave the solution due to their preference for a nonpolar environment. Collector also adsorbs on magnetite surface [10], but to a much lower degree thus the majority of collector molecules are expected to be present in the solution and capable to create froth. Compared to pure collector solution, magnetite decreased the frothing capacity. 


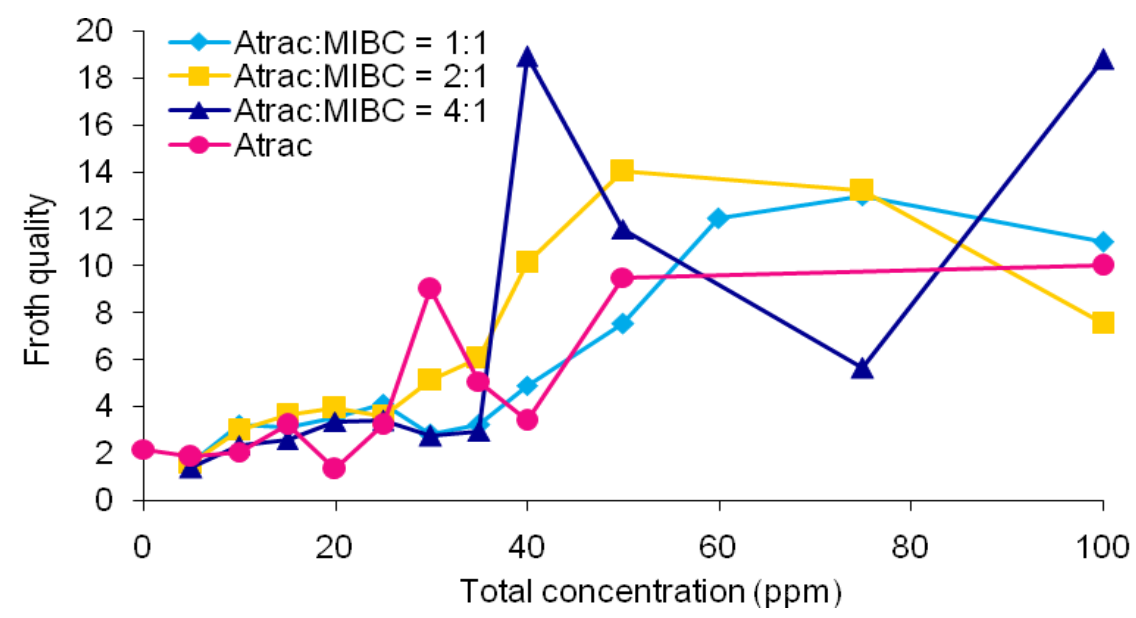

Fig. (13). Froth quality at different collector and frother composition as a function of total concentration at pH 8.5.

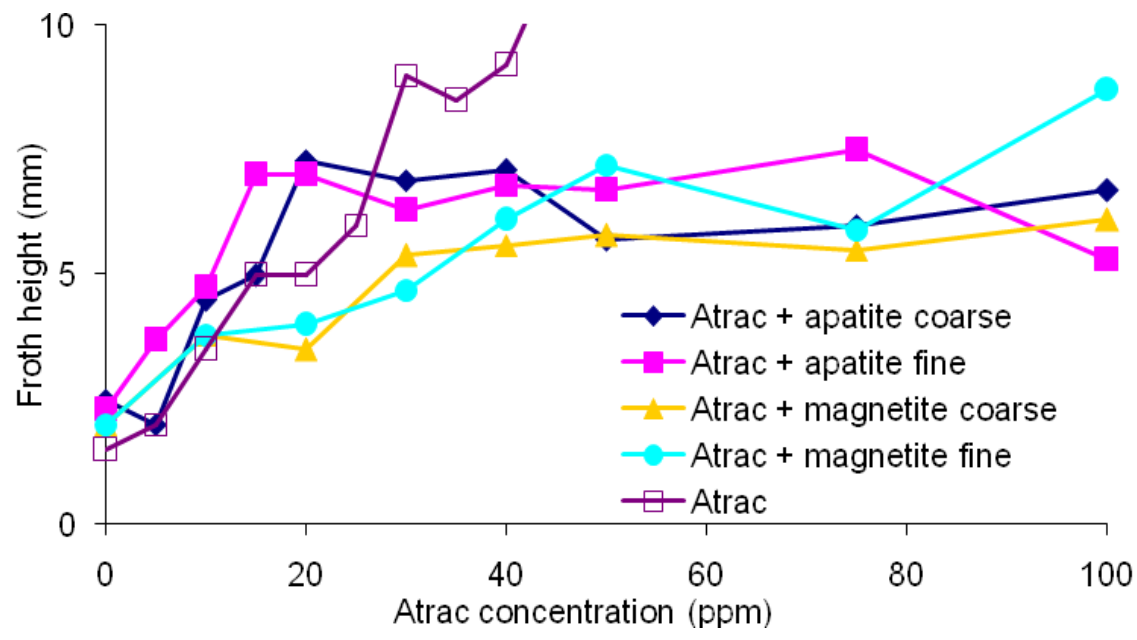

Fig. (14). Froth formation in the presence of apatite and magnetite particles as a function of collector concentration.

Levelling off froth height was observed at higher concentrations as before and the fine magnetite particles didn't impede much in froth production.

Froth quality heavily depended on the mineral type and particle size (Fig. 15). The coarse fractions had a much lower froth quality at any concentration compared to fine particles. The particles can disrupt the bubbles by their heavy weight. Generally magnetite is not capable to stabilize the froth, only at lower Atrac concentrations the addition of magnetite particles reached higher quality coefficient than with the pure collector froth. On the other hand apatite is forming stable flocs at any particle size. A sharp increase in froth quality was experienced up to 20 ppm of collector concentration. Beyond this concentration the stability decreased and increased again when the collector concentration increased. Particle size had a great influence on froth quality again and fine apatite particles created some incredibly stable frothflocs. Particles can act as a froth stabilizer if they block the liquid drainage, what the lighter smaller particles are definitely more capable to do than the coarse heavier ones. The sharp increase in froth stability at lower collector concentrations may be a consequence of not completely hydrophobic apatite particles. The particles are the most surface active, when their contact angle is around 90 degrees, e.g. half of the particle is in the liquid and half in the air like a surfactant molecule [5].

The amount of produced froth by MIBC frother in the presence of minerals is presented in Fig. (16). The fine size fractions of minerals promote froth formation, while the coarser particles had an opposite effect. Fine apatite particles increased the froth production at all concentrations compared to pure frother. Fine magnetite initially reduced the froth production at lower concentrations, but over $40 \mathrm{ppm}$ it performed similarly as fine apatite. Coarse apatite and magnetite decreased the amount of froth. Apatite of any particle size resulted in higher froth height than magnetite, it was also recognized visually.

Since a combination of collector and frother is used in actual practice, the influence of frother addition to collector solutions was examined and is presented in Figs. (17 and 18) for fine apatite particles. As mentioned previously, the collector created some floating apatite flocs on the surface, but not typical froth. When frother was introduced, froth formation is promoted at low collector concentration. Above $15 \mathrm{ppm}$ of collector, the amount of froth produced was depleted. The same effect was experienced for coarse size fractions as well. When the collector was redundant and frother concentration was low, the froth production was 


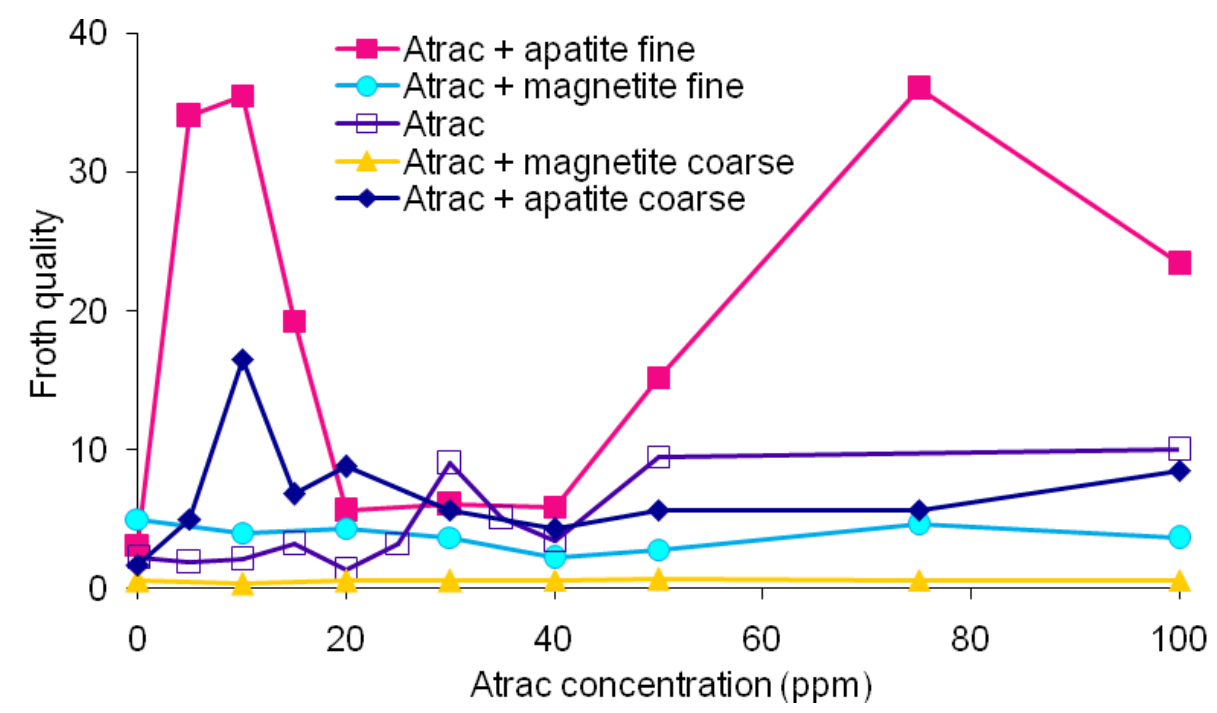

Fig. (15). Froth quality in the presence of apatite and magnetite particles as a function of collector concentration.

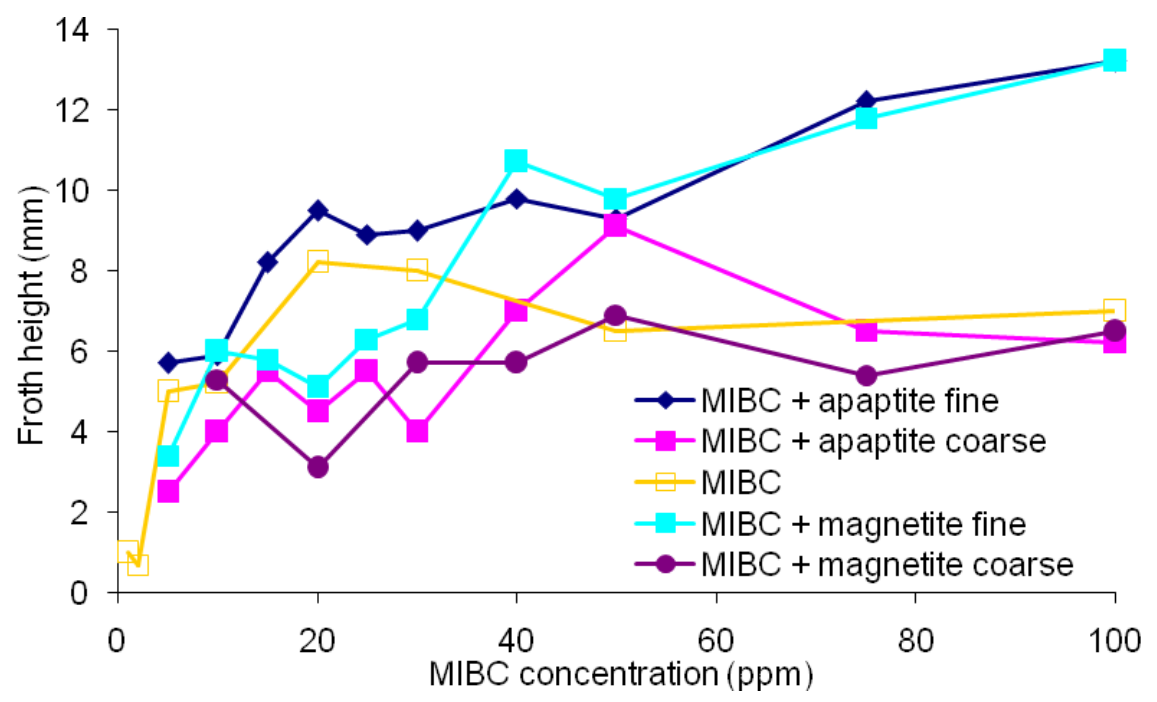

Fig. (16). Froth formation in the presence of apatite and magnetite particles as a function of frother concentration.

minimal and the mineral samples looked greasy. Frother had a stronger effect at low collector concentrations. At high collector concentrations, the frother content had a negligible effect on the froth as the curves were overlapping.

Froth quality is enhanced as can be seen in Fig. (18). Fine apatite resulted in a more stable froth up to $30 \mathrm{ppm}$ of collector. Coarse apatite stabilized the froth in between 15 and $50 \mathrm{ppm}$ of collector concentration. Higher frother addition caused higher stability. The stability of produced froth peaked at lower collector volumes with identical pattern. At lower collector concentration the apatite particles might be partially covered with collector and become surface active. Further frother addition only enhanced the extreme froth stability resulted from the presence of surface active particles. Hydrophobic particles can destabilize foams by forming lenses at the Plateau border of the foam, promoting dewetting of the film lamellae and causing bubble coalescence [11]. The presence of frother can enhance this effect by affecting the solvent conditions.
None of the mineral suspensions in the presence of surfactants behaved in the same way as pure surfactant solutions in froth formation. Surfactant solutions produced only little and low quality froth at acidic $\mathrm{pH}$, and the froth attributes rose only above $\mathrm{pH}$ 7-8 where the anionic collector solubilizes (data not shown). Both apatite and magnetite induced increased foamability at acidic $\mathrm{pH}$. Below $\mathrm{pH}$ 6, even magnetite, which tends to perform as a froth disruptor, increased the amount of froth formation. But both minerals flattened froth characteristics compared with the pure collector and frother solutions. The surfactants alone are having a sharp increase of froth above $\mathrm{pH}$ 7-8. The suspensions showed diminished froth formation with $\mathrm{pH}$ and increased frothing only above $\mathrm{pH}$ 9. But at the highest studied $\mathrm{pH}$ of the suspensions, the frothing was less than the pure solutions of collector and frother.

The quality of froth was enhanced with the presence of solids, even for magnetite below $\mathrm{pH}$ 8. For apatite the quality was increased several folds (data not shown). The quality of froth produced by apatite suspension peaked between $\mathrm{pH}$ 89. At the process $\mathrm{pH}$ of 8.5 the apatite rich froth is extremely 


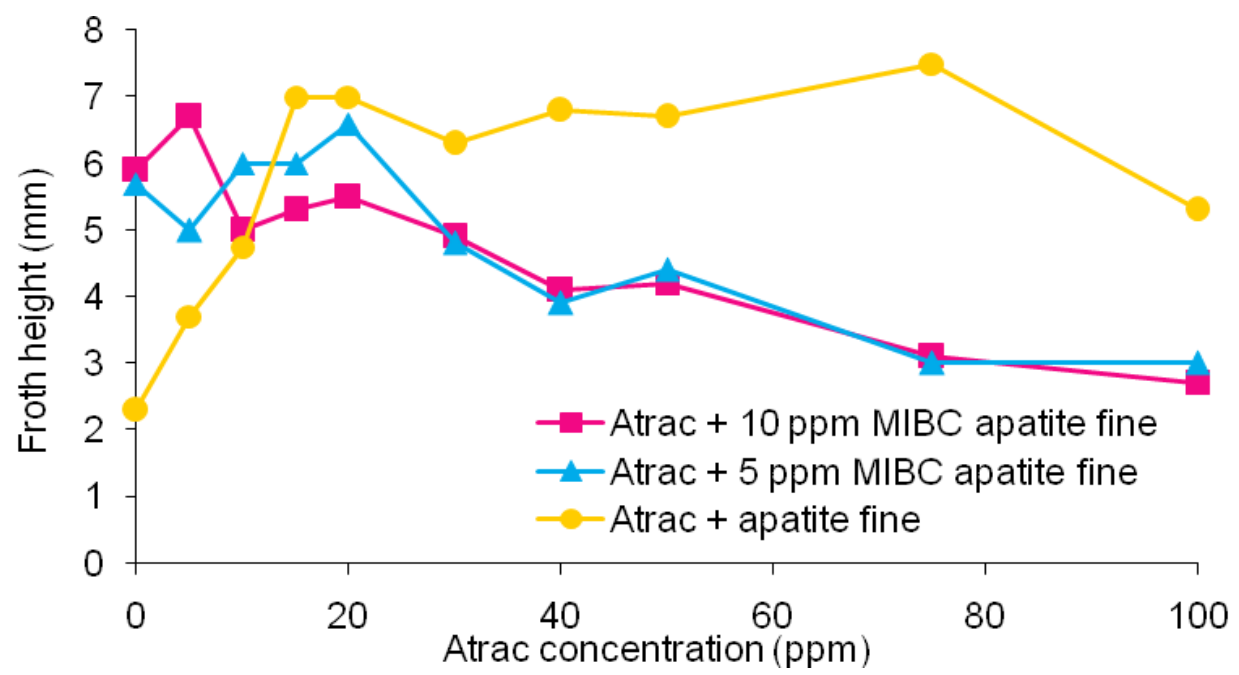

Fig. (17). Froth formation in the presence of fine apatite particles and with and without frother as a function of collector concentration.

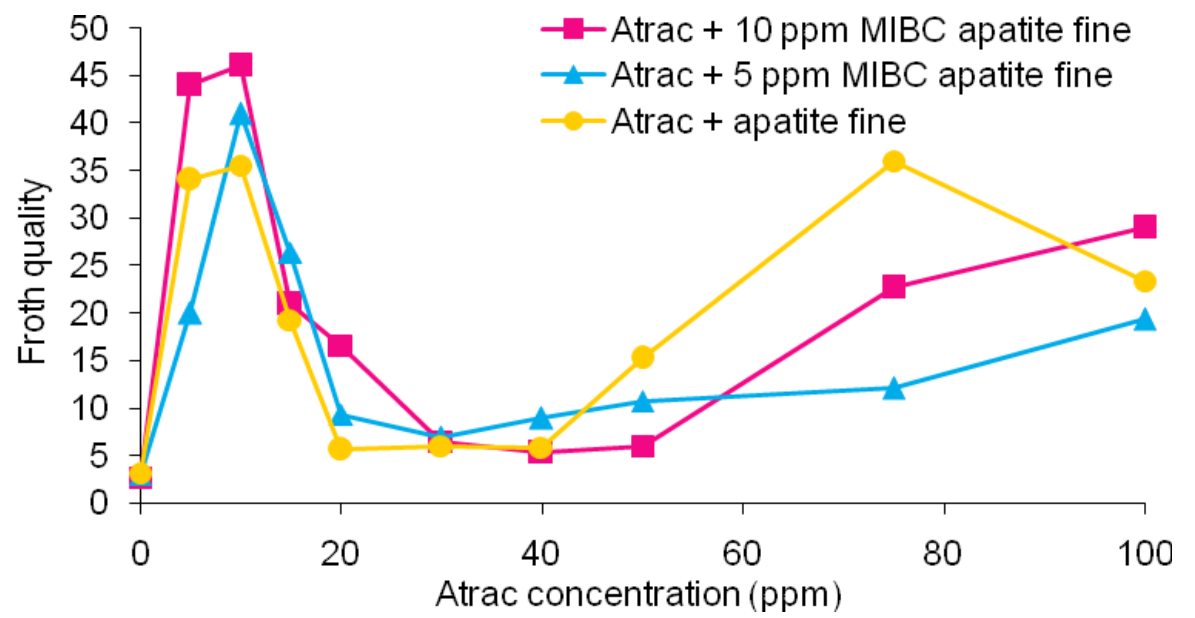

Fig. (18). Froth quality in the presence of fine apatite particles and with and without frother as a function of collector concentration.

stable. Magnetite suspension froth has constant quality throughout the $\mathrm{pH}$ scale with a minor enhancement at $\mathrm{pH} 7$ and 10. Magnetite enhances froth formation and quality at $\mathrm{pH}$ where the pure surfactants lack this ability but at the same time magnetite suppresses the frothing at $\mathrm{pH}$ where the surfactant solutions are frothing well.

\section{CONCLUSIONS}

Atrac collector is an anionic reagent and has a low CMC around $25 \mathrm{ppm}$. The amount of froth formation and its stability is dependent on concentration and $\mathrm{pH}$. Its increased frothing ability at higher $\mathrm{pH}$ is probably the result of electrostatic forces between the molecules positioning at the bubble lamella. MIBC frother displayed no CMC but has preferential adsorption at the air-water interface. Unstable and same amount of froth is produced regardless of frother concentration. A mixture of collector and frother generated higher froth volume with enhanced stability. As there is no interaction between collector and frother, the increase in froth production and stability is thought to be due to a change in electrostatic forces surrounding the collector molecule by the frother.

The presence of mineral particles either promotes or inhibits the froth phenomena depending on surface hydrophobicity or hydrophilicity, particle size, specific gravity and solids content. Higher amount of froth formation with high stability was observed with partially hydrophobic apatite particles, i.e., at lower collector concentrations, than at high concentrations where the frothing ability is lost with completely hydrophobic particles. In general apatite particles promoted froth formation of collector while the opposite effect was noticed with magnetite particles. The presence of frother at low collector concentrations in apatite suspension enhances the froth formation and its stability. It can be concluded that the higher stability of froth at LKAB flotation plant is due to the presence of partially hydrophobic apatite particles in the mineralised froth.

\section{CONFLICT OF INTERESTS}

The authors confirm that this article content has no conflicts of interest.

\section{ACKNOWLEDGEMENT}

The financial support from the Luossavaara-Kiirunavaara $\mathrm{AB}$ (LKAB) is gratefully acknowledged. One of the authors, Professor K. H. Rao, would also like to acknowledge the support from the research Centre for Advanced Mining and 
Metallurgy (CAMM), Luleå University of Technology, Luleå, Sweden.

\section{REFERENCES}

[1] M. J. Rosen, Surfactants and Interfacial Phenomena, $3^{\text {rd }}$ ed. Wiley: UK, 2004; p. 444.

[2] P. Swiatowski, A. Andersen, and A. Askenbom, "Process for froth flotation of oxide and salt type minerals andcomposition", US patent 5, 130, 037, 1992.

[3] K. Mysels, and A.T. Florence, "The effect of impurities on dynamic surface tension -- basis for a valid surface purity criterion”, J. Colloid. Interface Sci., vol. 43, p. 577, 1972.

[4] M. J. Schick, and A. H. Gillbert, "Effect of urea, guanidinium chloride, and dioxane on the c.m.c. of branched-chain nonionic detergents”, J. Colloid Sci., vol. 20, p. 464, 1965.

[5] K. Holmberg, B. Jonsson, and B. Kronberg, Surfactants and Polymers Aqueous Solutions, $2^{\text {nd }}$ ed. Wiley: UK, 2003; p. 545.
[6] D. O. Shah, Micelles, microemulsions and monolayers, Marcel Dekker, NY, 1998; p. 632.

[7] B. K. Jha, A. Patist, and D. O. Shah, "Effect of antifoaming agents on the micellar stability and foamability of Sodium Dodecyl Sulfate Solutions”, Langmuir, vol. 15, p. 3042, 1999.

[8] S. H. Herzfeld, M. L. Corrin, and W. D. Harkins, "The effect of alcohols and of alcohols and salts on the critical micelle concentration of Dodecylammonium Chloride", J. Phys. Chem., vol. 54, p. 271, 1950.

[9] S. Miyagishi, "The effect of organic additives on the thermodynamic parameters of micellization”, Bull. Chem. Soc. Japan, vol. 49, p. 34, 1976.

[10] K. H. Rao, R.K. Dwari, S. Lu, and A. Vilinska, "Somasundaran. Mixed ionic/non-ionoc collector in phosphate gangue flotation from magnetite fines", IMPC 2010.

[11] G. Wang, R. Pelton, A. Hrymak, N. Shawafaty, and Y.M. Heng, "On the role of hydrophobic particles and surfactants in defoaming”, Langmuir, vol. 15, p. 2202, 1999.

(C) Vilinska et al.; Licensee Bentham Open.

This is an open access article licensed under the terms of the Creative Commons Attribution Non-Commercial License (http://creativecommons.org/licenses/ by-nc/3.0/) which permits unrestricted, non-commercial use, distribution and reproduction in any medium, provided the work is properly cited. 